\title{
A Study of Classics-Reading Curriculum, Classics-Reading Promotion, and Classics-Reading Effect Modeling Exploration in Elementary Schools
}

\author{
Chuen-An Tang, ${ }^{1}$ Kuang-Ming Chen, ${ }^{2}$ Li-Chuan Chang, ${ }^{3}$ and Deng-Shun Lin ${ }^{2}$ \\ ${ }^{1}$ Graduate Institute of Education, National Cheng Kung University, Tainan 701, Taiwan \\ ${ }^{2}$ Department of Chinese Language and Literature, National University of Tainan, Tainan 700, Taiwan \\ ${ }^{3}$ Department of Nursing, Tajen University, Pingtung 907, Taiwan \\ Correspondence should be addressed to Deng-Shun Lin; linem@mail.nutn.edu.tw
}

Received 14 September 2013; Accepted 29 November 2013; Published 2 January 2014

Academic Editor: Teen-Hang Meen

Copyright (C) 2014 Chuen-An Tang et al. This is an open access article distributed under the Creative Commons Attribution License, which permits unrestricted use, distribution, and reproduction in any medium, provided the original work is properly cited.

\begin{abstract}
The purposes of this study are to test reliabilities and validities of classics-reading curriculum (CRC) scale, classics-reading promotion (CRP) scale, and classics-reading effect (CRE) scale and to examine the relationships between CRC, CRP, and CRE in elementary schools through applying CORPS framework. The pilot sample and formal sample contain 141 and 500 participants from elementary school faculties and classics-reading volunteers in the north, central, south, and east regions of Taiwan. The findings indicate that Cronbach $\alpha$ coefficients of curriculum cognition (CC), curriculum teaching (CT), inside-school promotion (IP), outside-school promotion (EP), learning effect (LE), and class management effect (CME) subscales are .88, .85, .93, .91, .91, .94 , respectively, through exploratory factor analysis and they have good internal reliabilities and construct validities, respectively, through confirmatory factor analysis. Moreover, CC, CT, IP, and EP have positive influences on LE (standardized coefficients .34, $.25, .14$, and .22) and on CME (standardized coefficients .41, .14, .14, and .20), respectively. CC, CT, IP, and EP can explain $69 \%$ of LE and $61 \%$ of CME. The model is supported by the data. Lastly, this study proposes some suggestions regarding the classics-reading education for elementary schools.
\end{abstract}

\section{Introduction}

Since mandarin text books were written in vemacular Chinese no longer in classical Chinese in elementary schools (ESs) in 1920, the trend of classics-reading (CR) has been going down [1]. In 1994, Tsai-Kui Wang in hopes of opening children's pure hearts through great ancient books in the Chinese culture and laying good foundations for developing wonderful personalities under the gradual changes and influences started to promote CR for children, so that the traditions of the Chinese culture can be passed on [2]. He has been giving speeches everywhere for propagation of the philosophy of CR education and held CR workshops for teachers annually to pass on the methods and skills of CR teaching during 19 years.

In 1989, UNESCO holds for the twenty-first century conference and points out that the challenges of morality, ethics, and values will be the first one that people face in the twentyfirst century [3]. Character Counts offers six pillars of character in 1992 [4]. New century's education is that becoming good is more important than getting smart for the students. Global Education Council points out that the new education is characterized by that. Building noble-character citizens will be a focus point of education in the world.

Because the education philosophy of Confucian is concerned about character training, the trend of the new education helps to promote the CR education in the society and school. The twenty-first century is an era that English supports and competes against Chinese mutually, and Chinese ability cannot easily be ignored [5]. The CR education has flourished not only in the society but also in the schools since Wang and the numerous nongovernmental CR organizations struggled to promote CR education from 1994 to the present. Although there has been an ongoing debate of the CR 
education $[1,6-8]$, the CR education workshops for teachers [9-11], the promotion of CR education in all Hualien County's primary schools [12], the national CR examination, and so on indicate that the CR education for ESs still develops and grows sustainably in the practice of educational reform.

There are about 1.5 million children participated in CR until 2007 [13]. The trend of CR has led to many studies regarding $\mathrm{CR}$ for children. In the National Digital Library of Theses and Dissertations in Taiwan, there are at least 53 master's theses and doctoral dissertations regarding CR education, dated from 1999 to Jan 2013. The keys to whether CR education for children can succeed include insights of, emphases on, plans for, and implementation and effects of CR education for the first-line school faculties and CR volunteers. In other words, CR philosophy, degrees of understanding CR, CR teaching, and planning CR activities of school faculties and $\mathrm{CR}$ volunteers determine effects of $\mathrm{CR}$ education for children. Moreover, there have not been enough studies about CR education with elementary school faculties and CR volunteers being the research subjects. Therefore, it is necessary to explore the degrees of understanding CR ideals, CR teaching, plans about CR activities, and CR effect for school faculties and CR volunteers.

Firstly, the specific educational objectives of the CR education plans implemented by many ESs include inspiring humanity, passing on the Chinese culture, developing humanistic spirit, and discovering potentials. CR teachers should not only know the importance of $\mathrm{CR}$ and realize the values of $\mathrm{CR}[14,15]$ but also must understand the basic principles of CR education: one purpose, two natures, three principles, four standards, and five characteristics [16].

The findings of the empirical studies indicate that over $77 \%$ of teachers believed that CR teachers can recognize the values of classics, and over 35\% of teachers believed that children should start reading classics as early as possible [17]. The basic principle of CR teaching for children is allowing children to contact, read, and recite classics more often [1]. Currently, most teachers usually develop various recitation methods in the ESs, such as fan-tan, taking turns, and passing challenges. Teachers always have different practices to interpret contents of classics. In the aspect of rewards and punishments, verbal praises instead of material rewards and encouragement instead of punishments are stressed [18, 19]. Above those, this study creates a classics-reading curriculum (CRC) scale including curriculum cognition (CC) and curriculum teaching (CT). The former represents the degree of understanding the CR philosophy and the later represents the teaching methods for CR.

Secondly, ESs often invite experts or scholars to give speeches regarding CR education in order to clear up teachers' and parents' doubts about CR education and to offer teachers and parents a chance to further understand the importance of CR education, so that they would then accept and recognize CR education [15]. CR achievement exhibitions are usually held for the purposes of offering community residents to know $\mathrm{CR}$, increasing teachers' willingness to engage in $C R$, increasing parents' willingness to become $C R$ volunteers, and even improving schools' enrollment rates $[12,20-22]$. ESs implement various CR activities, such as CR webpage [12], CR volunteer trainings or summer/winter CR camps [22], CR education parenting seminars, parent-child CR curriculums or adult CR curriculums, CR education workshops for teachers [9-11], cross-school CR exchange activities, Cross-Strait CR Seminar [20], and the SuzhouTaipei Chinese Classic Poems and Prose Exchange Activity Series [23]. Above those, this study creates a classics-reading promotion (CRP) scale, including intramural promotion (IP) and extramural promotion (EP). The former represents various inside-school CR activities and plans promoting CR and the later represents various outside-school CR activities and plans promoting CR.

Thirdly, the findings of many empirical studies show that there are not only positive views on CR education for children but also affirmation to the overall effects of promoting CR education for children, such as improving memory [21-27], enhancing concentration [28], understanding more about the culture $[29,30]$, reducing ill behaviors and fighting, avoiding arguments, accepting advises, showing understanding for others, improving interpersonal interactions, becoming more mature $[15,19,25,28,30]$, having harmonious class atmosphere, making class management easier [17, 24, 31, 32], helping to promote moral education $[26,28]$, increasing close parent-child interactions $[24,28]$, and increasing teacherstudent interactions $[17,28,32]$. In other words, CR can not only improve the effects of students' learning but also enhance the effects of teachers' class management. Above those, this study creates a classics-reading effect (CRE) scale including learning effect (LE) and class management effect (CME). The former represents the effects about moral, concentration, memory, and so on, and the later represents the effects about class order, class atmosphere, teacher-student relationship, parent-child relationship, and so on.

Fourthly, the nonprofit organization originated in the United States of America. The school is a nonprofit organization of education [33, 34]. Seetoo [35] constructs CORPS framework for nonprofit organization's management. CORPS consists of five basic factors and is an acronym for Client, Operation, Resource, Participant, and Service. The Client factor (C) means service objects. The Operation factor (O) contains plan, execution and control of the activities. The Resource factor (R) includes financial resources, material resources, and resource providers. The Participant factor $(\mathrm{P})$ consists of full-time staff and volunteers. The Service factor (S) means that the organization provides services for objects. Further, the CORPS operation model means that an organization provides some valuable services (S) for some people in society $(\mathrm{C})$ through implementing numerous organized activities $(\mathrm{O})$ and combining with the participants $(\mathrm{P})$, financial resources, material resources, and resource providers (R) (see Figure 1).

The research directions of 34 empirical studies are roughly classified into six aspects including participant, resource, curriculum, promotion, effect, and client. They are categorized according to the characters of the CORPS factors. Because school staffs and CR volunteers are the central executors in the CR education for ESs, the $\mathrm{P}$ contains principals, directors, teachers, and CR volunteers. The financial 


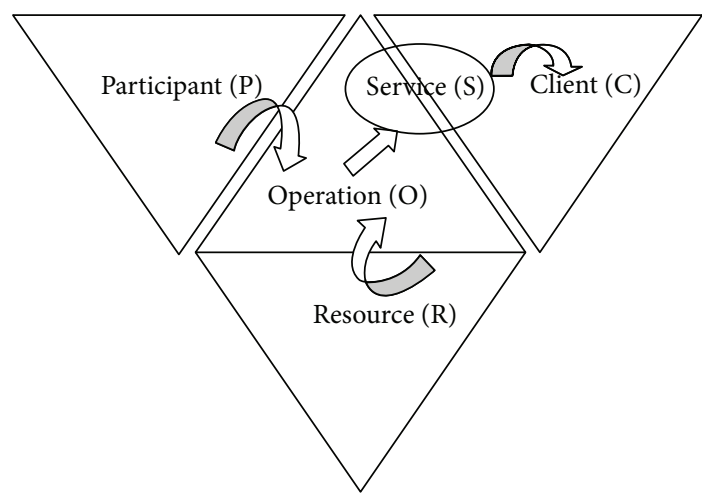

FIGURE 1: CORPS operation model (graph source from Seetoo [35]).

resources and material resources are needed in the implementation of CR education for ESs. Those resources always are provided by the school or parents association or parents. Thus, the $\mathrm{R}$ consists of financial resources, material resources, and resource providers. The $\mathrm{O}$ contains CRC including CC and CT and CRP including IP and EP. The $S$ consists of CRE including LE for students and CME for teachers. Because CRE is aimed at students and teachers mainly the $\mathrm{C}$ includes students and teachers.

The CRE can be affected separately by principals, directors, teachers, CR volunteers, and various resources [15, $26,36,37]$. In other words, the Participant factor and the Resource factor should influence the Operation factor. The CR aim and philosophy for the teachers can affect the implementation of CR education in the school and then can affect CRE $[19,22,38]$. Therefore, CRC should relate to CRE. If the school wants to reach the aim and effect for CR education, and there should be a comprehensive implementation plan and activities for CR education in the school [35]. Therefore, CRP should relate to CRE. In other words, the Operation factor should influence the Service factor. Further, the CORPS operation model for CR education in the school means that the CR education of the school provides CRE (S) for students and teachers in the school (C) through the CRC and CRP $(\mathrm{O})$, combining with the principals, directors, teachers, CR volunteers $(\mathrm{P})$, various financial resources, material resources, and resource providers $(\mathrm{R})$.

The research directions of 34 empirical studies all focus on certain selected aspects. The growing effects of CR are slow because CR must be carried out for a long time [15, 26, 27, 30, 39]. And it is not easy for the effects of CR to last. One of the key reasons is that there is no overall plan for CR education [36]. Therefore, it is essential to explore the influences of degrees of understanding the CR philosophy, CR teaching, and CR activity planning of school faculties and CR volunteers on CR effects.

In addition, because there is the lack of overall management concept for the combination of those aspects about CR education's research, it is important to integrate those aspects. However, the literatures about the principals, directors, teachers, CR volunteers, and resources having influence on CRE for CR education in ESs are insufficient, this study only examines the relationships between CRC, CRP, and CRE for the principals, directors, teachers, and CR volunteers through applying CORPS framework constructed by Seetoo [35] for nonprofit organization's management (see Figure 2). In other words, this study only investigates the influence of Operation factor on Service factor. Lastly, some related suggestions are proposed for CR education in ESs.

Above those, the research questions are as follows.

(1) Dose each of CRC scale, CRP scale, and CRE scale has a good internal reliability?

(2) Dose each of CRC scale, CRP scale, and CRE scale has a good construct validity?

(3) Dose CRC and CRP influence CRE? (see Figure 2).

\section{Method}

2.1. Participants and Procedure. Because CR education is not yet a part of the formal elementary school education system, this study adopts the purposive sampling method. H. E. Tinsley and D. J. Tinsley [40] suggest that 10 subjects or 5 subjects at a minimum are required for every variable being analyzed. Although there is no correct rule for estimating sample size for SEM, recommendations are for a size ranging between 100 and 200 [41]. Reisinger and Turner [42] showed that the sample size should be as a rule of thumb at least 5 times the number of parameters. Thus, according to the statistics regarding the numbers of elementary school faculties in northern, central, southern, and eastern Taiwan $[43,44]$ and 82 estimated parameters in the model 1 of this study, the pilot sample of 150 subjects and the formal sample of 515 subjects are selected from principals, directors, teachers, and CR volunteers of ESs in the northern, central, southern, and eastern Taiwan from Oct 2012 to Jan 2013. With the response rate over $93 \%$, there are 141 valid pilot samples and 500 valid formal samples.

2.2. Measure. This study adapts CRC scale, CRP scale, and CRE scale developed by Tang [45] and retests the validity and reliability of each of the three scales. The pretest questionnaire contained 40 items, 11 items of CRC scale, 12 items of CRP scale, 12 items of CRE scale, and 5 demographic items. Responses are judged on 6-point Likert type scales for each item $(1=$ strongly disagree and $6=$ strongly agree $)$.

2.3. Exploratory Factor Analysis. 141 records are used to identify factor structures of each of CRC scale, CRP scale, and CRE scale. 11, 12, 11 items are remained in each of them, respectively, through exploratory factor analysis (EFA) using SPSS 17.0. CRC scale contains CC subscale (5 items) and CT subscale (6 items), CRP scale contains IP subscale (6 items) and EP subscale (6 items), and CRE scale contains LE subscale (5 items) and CME subscale (6 items) through exploratory factor analysis (EFA) using SPSS 17.0. Each total variance explained of three scales is $63.18 \%, 72.52 \%$, and $76.38 \%$. Cronbach [46] claims that $.8 \leqq$ Cronbach $\alpha<.9$ represents a good internal consistency. Each Cronbach $\alpha$ coefficient of CC, CT, IP, EP, LE, and CME subscales is .88, .85, .93, 


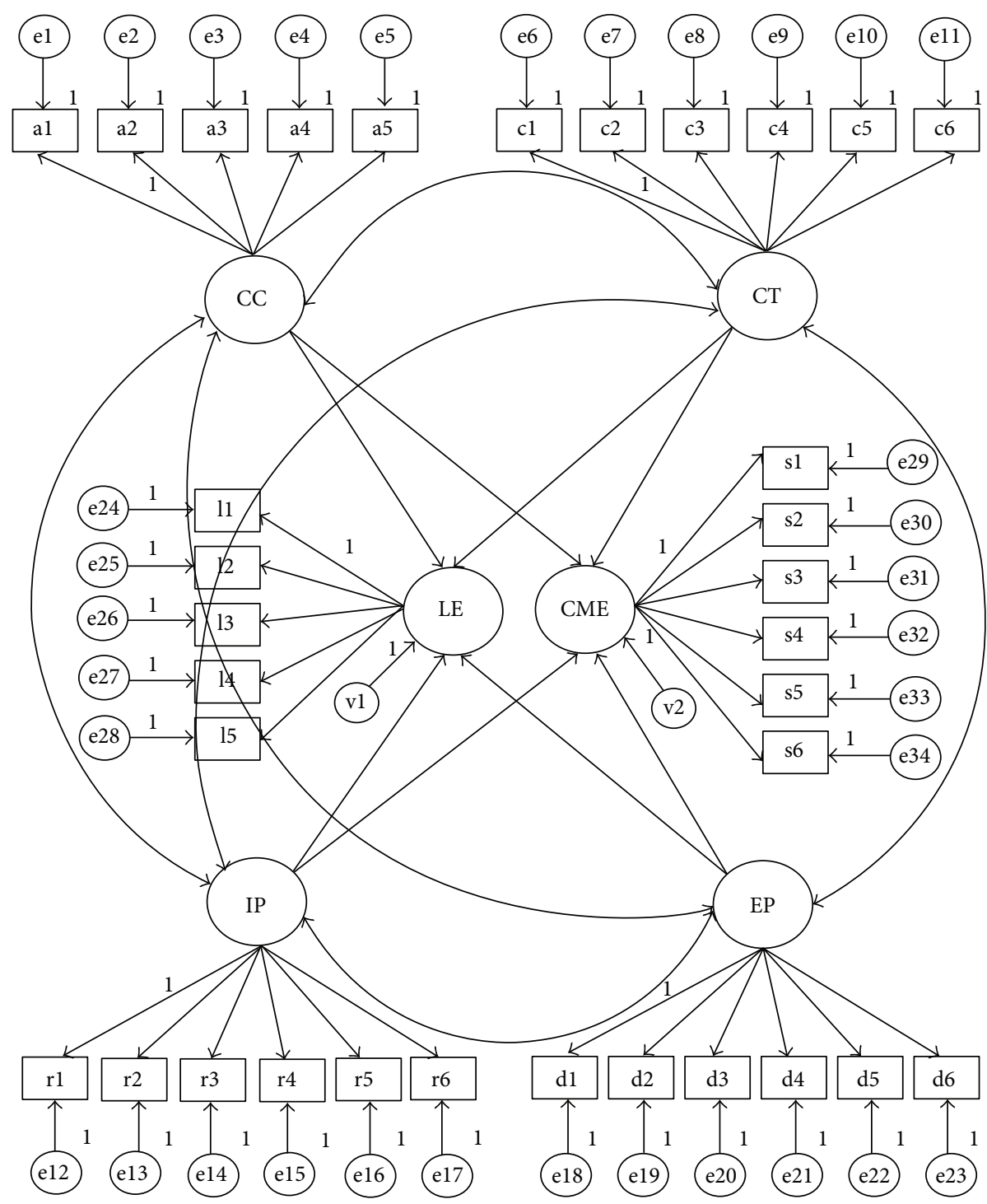

FIgURE 2: The hypothetical constructs of relationships between CRC, CRP, and CRE in model 1.

$.91, .91$, and .94 . Those indicate that all subscales are with good internal reliabilities.

2.4. Confirmatory Factor Analysis and Structural Equation Modeling. 500 records are used to test reliability and validity of each of CRC scale, CRP scale, and CRE scale through confirmatory factor analysis (CFA) and to examine model 1 (see Figure 2) using Amos 17.0. Eleven fit indices criteria are chosen: chi-square ratio $\left(\chi^{2} / \mathrm{df}\right)<5$ [47], goodness of fit index $(\mathrm{GFI})>.90$, adjusted goodness of fit index $(\mathrm{AGFI})>$ .9 , normed incremental fit index $(\mathrm{NFI})>.90$, comparative fit index $(\mathrm{CFI})>.90$, parsimony normed fit index $(\mathrm{PNFI})>.5$, parsimony goodness of fit index $(\mathrm{PGFI})>.5$, value of saturated model $<$ expected cross-validation index $(\mathrm{EVCI})<$ value of independent model, value of saturated model $<$ Akaike information criteria (AIC) $<$ value of independent model [48], root mean square $(\mathrm{RMR})<.05$ [47], and root mean square error of approximation $($ RMSEA $)<.08$ [49].
TABLE 1: Mean, SD, and correlation coefficients of all subscales $(N=$ $500)$.

\begin{tabular}{lccccccc}
\hline Subscale & Mean $(\mathrm{SD})$ & CC & CT & IP & EP & LE & CME \\
\hline CC & $5.00(.63)$ & 1 & & & & & \\
CT & $5.07(.60)$ & $.64^{* *}$ & 1 & & & & \\
IP & $4.80(.67)$ & $.62^{* *}$ & $.61^{* *}$ & 1 & & & \\
EP & $4.75(.66)$ & $.53^{* *}$ & $.56^{* *}$ & $.73^{* *}$ & 1 & & \\
LE & $5.07(.67)$ & $.68^{* *}$ & $.63^{* *}$ & $.66^{* *}$ & $.62^{* *}$ & 1 & \\
CME & $4.77(.75)$ & $.64^{* *}$ & $.57^{* *}$ & $.63^{* *}$ & $.58^{* *}$ & $.72^{* *}$ & 1 \\
\hline
\end{tabular}

Note. SD: standard deviation ${ }^{* *} P<.01$.

\section{Results and Discussion}

3.1. Descriptive Statistics and Correlations. As shown in Table 1, each mean of CC, CT, IP, EP, LE, and CME from 500 records is $>4.70$. It indicates that most of principals, directors, 
TABLE 2: Each of fit indices of CRC scale, CRP scale, and CRE scale $(N=500)$.

\begin{tabular}{|c|c|c|c|c|c|c|c|c|c|}
\hline Index & $\begin{array}{c}\chi^{2} / \mathrm{df} \\
<5\end{array}$ & $\begin{array}{l}\text { GFI } \\
>.9 \\
\end{array}$ & $\begin{array}{c}\text { AGFI } \\
>.9 \\
\end{array}$ & $\begin{array}{l}\text { NFI } \\
>.9 \\
\end{array}$ & $\begin{array}{l}\text { CFI } \\
>.9 \\
\end{array}$ & $\begin{array}{l}\text { RMR } \\
<.05 \\
\end{array}$ & $\begin{array}{c}\text { RMSEA } \\
<.08 \\
\end{array}$ & $\begin{array}{c}\text { PNFI } \\
>.5 \\
\end{array}$ & $\begin{array}{c}\text { PGFI } \\
.5 \\
\end{array}$ \\
\hline$\overline{\text { CRC }}$ & $4.01^{* * *}$ & .94 & .91 & .94 & .95 & .03 & .078 & .74 & .61 \\
\hline CRP & $4.62^{* * *}$ & .92 & .88 & .94 & .95 & .028 & .085 & .73 & .63 \\
\hline CRE & $12.66^{* * *}$ & .82 & .73 & .89 & .89 & .035 & .154 & .70 & .54 \\
\hline
\end{tabular}

Note. ${ }^{* * *} P<.001$.

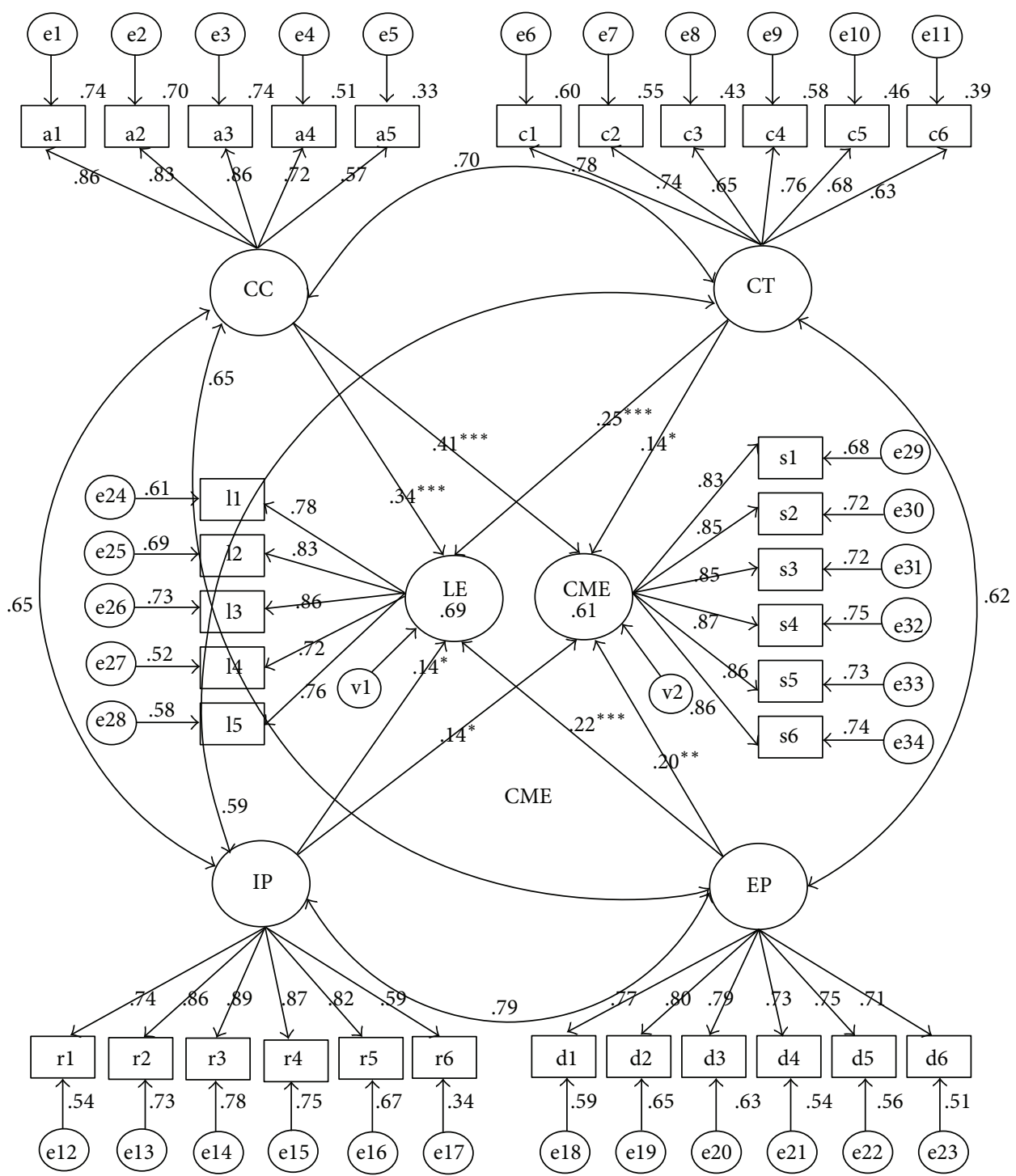

FIgURE 3: Standardized coefficients of CRC and CRP to CRE in model 1.

teachers, and CR volunteers of ESs have the degree of understanding the CR philosophy, accept teaching methods for CR, promote roughly various CR related inside-school and outside-school activities and plans, and indentify effects of CR for students and teachers. Any two of CC, CT, IP, EP, LE, and CME are significantly and positively correlated, and all correlation coefficients are between .53 and .73.

3.2. CFA. CFA is applied with the 500 valid formal samples. As shown in Table 2, the internal quality and external quality of CRC and CRP and the internal quality of CRE are good. Although the external quality of CRE is not ideal, it is better than moderate and is acceptable.

As shown in Table 3, it indicates the following: (1) because each composite reliability (C.R.) of the all latent variables is $>.60$ [50], there is a good internal reliability for each of CRC scale, CRP scale, and CRE scale. (2) Because each standardized factor loading (SFL) of the all observable variables is $\geqq .50$ and all $P$ values are significant and each average variance extracted (AVE) of the all latent variables is between .50 
TABle 3: Parameters estimation for CC, CT, IP, EP, LE, and CME subscales $(N=500)$.

\begin{tabular}{|c|c|c|c|c|c|c|c|c|c|c|}
\hline Subscale & $\begin{array}{l}\text { SFL } \\
\geq .5\end{array}$ & $\begin{array}{c}\text { SMC } \\
\geq .3\end{array}$ & $\begin{array}{c}\text { C.R. } \\
>.6\end{array}$ & $\begin{array}{l}\text { AVE } \\
>.5\end{array}$ & Subscale & $\begin{array}{l}\text { SFL } \\
\geq .5\end{array}$ & $\begin{array}{c}\text { SMC } \\
\geq .3\end{array}$ & $\begin{array}{c}\text { C.R. } \\
>.6\end{array}$ & $\begin{array}{c}\text { AVE } \\
>.5\end{array}$ & CORR. COEF. \\
\hline$\overline{\mathrm{CC}}$ & & & .88 & .61 & $\mathrm{CT}$ & & & .86 & .50 & $\mathrm{CC}$ and $\mathrm{CT}$ \\
\hline al & $.87^{* * *}$ & .77 & & & $\mathrm{cl}$ & $.79^{* * *}$ & .62 & & & .69 \\
\hline a2 & $.84^{* * *}$ & .71 & & & c2 & $.74^{* * *}$ & .55 & & & \\
\hline a3 & $.86^{* * *}$ & .74 & & & c3 & $.64^{* * *}$ & .41 & & & \\
\hline a4 & $.71^{* * *}$ & .50 & & & $c 4$ & $.78^{* * *}$ & .61 & & & \\
\hline \multirow[t]{2}{*}{ a5 } & $.51^{* * *}$ & .26 & & & c5 & $.67^{* * *}$ & .45 & & & \\
\hline & & & & & c6 & $.60^{* * *}$ & .36 & & & \\
\hline IP & & & .90 & .64 & $\mathrm{EP}$ & & & .89 & .58 & IP and EP \\
\hline $\mathrm{r} 1$ & $.73^{* * *}$ & .64 & & & $\mathrm{~d} 1$ & $.77^{* * *}$ & .58 & & & .79 \\
\hline $\mathrm{r} 2$ & $.86^{* * *}$ & .74 & & & $\mathrm{~d} 2$ & $.81^{* * *}$ & .66 & & & \\
\hline r3 & $.89^{* * *}$ & .79 & & & $\mathrm{~d} 3$ & $.79^{* * *}$ & .62 & & & \\
\hline $\mathrm{r} 4$ & $.86^{* * *}$ & .74 & & & $\mathrm{~d} 4$ & $.74^{* * *}$ & .55 & & & \\
\hline $\mathrm{r} 5$ & $.82^{* * *}$ & .67 & & & d5 & $.75^{* * *}$ & .56 & & & \\
\hline r6 & $.58^{* * *}$ & .34 & & & d6 & $.71^{* * *}$ & .50 & & & \\
\hline $\mathrm{LE}$ & & & .89 & .63 & CME & & & .94 & .73 & LE and CME \\
\hline 11 & $.78^{* * *}$ & .63 & & & s1 & $.83^{* * *}$ & .73 & & & .78 \\
\hline 12 & $.81^{* * *}$ & .66 & & & s2 & $.85^{* * *}$ & .72 & & & \\
\hline 13 & $.86^{* * *}$ & .74 & & & s3 & $.85^{* * *}$ & .72 & & & \\
\hline 14 & $.75^{* * *}$ & .56 & & & s4 & $.87^{* * *}$ & .76 & & & \\
\hline \multirow[t]{2}{*}{15} & $.77^{* * *}$ & .59 & & & s5 & $.85^{* * *}$ & .72 & & & \\
\hline & & & & & s6 & $.86^{* * *}$ & .74 & & & \\
\hline
\end{tabular}

Note. SFL: standardized factor loading; SMC: squared multiple correlation.

C.R.: composite reliability; AVE: average variance extracted.

CORR. COEF.: correlation coefficient; ${ }^{* * *} P<.001$.

TABLE 4: Summary of the overall fit indices for model $1(N=500)$.

\begin{tabular}{|c|c|c|}
\hline Absolute fit measures & & Accept or not \\
\hline$\overline{\chi^{2}}$ & 1706.79 & \\
\hline $\mathrm{df}$ & 513 & \\
\hline$\chi^{2} / \mathrm{df}<5$ & 3.33 & $\bigcirc$ \\
\hline$P$ value $>.05$ & $<.001$ & $\mathrm{X}$ \\
\hline $\mathrm{RMR}<.05$ & .034 & O \\
\hline RMSEA $<.08$ & .068 & $\mathrm{O}$ \\
\hline GFI $>.9$ & .83 & $\mathrm{X}$ \\
\hline AGFI $>.9$ & .80 & $\mathrm{X}$ \\
\hline Value of saturated model $<$ EVCI $<$ value of independent model & $2.39<3.75<26.54$ & O \\
\hline Incremental fit measures & & Accept or not \\
\hline $\mathrm{NFI}>.9$ & .87 & $\mathrm{X}$ \\
\hline IFI $>.9$ & .91 & O \\
\hline $\mathrm{CFI}>.9$ & .91 & O \\
\hline Parsimonious fit measures & & Accept or not \\
\hline $\mathrm{PNFI}>.5$ & .80 & O \\
\hline PGFI $>.5$ & .71 & O \\
\hline Value of saturated model $<$ AIC $<$ value of independent model & $1190.00<1870.79<13241.07$ & O \\
\hline
\end{tabular}

and .73, there is a good convergent validity for each of CRC scale, CRP scale, and CRE scale. (3) Because the correlation coefficients among CRC, CRP, and CRE are .69, .79, and .78 and because each of them is under .85 [51], there is a discriminant validity for each of the three scales.

\subsection{Structure Model}

3.3.1. Estimation Method. Because the skew coefficients and kurtosis coefficients of all variables are between -.73 and -.14 and between -.74 and .91 , this study chooses to adopt 
the method of maximum likelihood to estimate the parameters of model 1 .

3.3.2. Offending Estimation. All the standardized parameter estimations are between .14 and .89 , not too close to 1 , and the plus or minus signs of the estimations of parameters are consistent. All the standard errors of the estimations are between .012 and .048, not very large. There is no negative error variable and all the error variables are significant. Therefore, model 1 meets the 5 preliminary fit criteria [52].

3.3.3. Evaluation of the Overall Goodness-of-Fit. As shown in Table 4 , the values of $\chi^{2} / \mathrm{df}$, RMR, RMSEA, ECVI, IFI, CFI, PNFI, PGFI, and AIC are all acceptable, but $P$ value is significant. The values of GFI, AGFI, and NFI are nearly accepted. Therefore, the empirical data are fitted in model 1.

3.3.4. To Test Goodness-of-Fit for Internal Structure. As shown in Table 5, the parameter estimations of the 34 observed indices are all significant, each SEL of them is $\geq .5$, each AVE of the six latent variables is $>.5$, and each C. R. of them is $>.6$ [50]. Therefore, the internal quality of model 1 is good.

3.4. Direct and Total Effect. As shown in Figure 3, the effects of CC on LE and CT on LE are $.34^{* * *}, .25^{* * *}$. Those results are consistent with the findings of many studies which had pointed out that CRC would influence LE $[15,22,24,26,28$, 29]. The effects of CC on CME and CT on CME are $.41^{* * *}$, $.14^{*}$. Those results are consistent with the findings of many studies which had pointed out that CRC would further influence CME $[17,19,24,25,30-32,53]$. The effects of IP on LE and EP on LE are $.14^{*}, .22^{* * *}$. The effects of IP on CME and EP on CME are $.14^{*}, .20^{* *}$. Those results are consistent with the findings of which had pointed out that CRP would influence LE and CME $[17,22,36,54]$. CC, CT, IP, and EP can explain $69 \%$ of $\mathrm{LE}$ and $61 \%$ of CME.

Above those, the influences of CC on LE and on CME are both the largest. It indicates that $\mathrm{CC}$ is the main factor influencing LE and CME. The influences of CC and CT on LE and CC on CME are larger than the influences of IP and EP on LE and on CME. It implies that to promote CR, CR philosophy plays an important role. The influences of IP on LE and on CME are both rather small. The main reason may be that teachers do not entirely believe that CR achievement exhibitions are helpful for their teaching [36], and then the influences on LE are not strong. The influences of IP on LE and on CME are smaller than the influences of EP on LE and on $\mathrm{CME}$. The reasons may be that because CR education is not a part of the formal education system, CR education policies are not compulsory; because manpower and resources of ESs are limited and there are a lot of school activities other than CR activities, teachers do not want to participate in promoting CR actively, and then those limit to promote CR activities and lead to a rather small influences of IP on LE and CME [17]. Although those reasons may lead to a smaller influence of CRP on CRE, CRP cannot be ignored for the classicsreading education in the school.
TABle 5: SEL, $R^{2}$, AVE, and C. R. in model 1.

\begin{tabular}{|c|c|c|c|c|c|}
\hline L.V. & O.V. & SEL $\geq .5$ & $\operatorname{SMC}\left(R^{2}\right)$ & AVE $>.5$ & C.R. > .6 \\
\hline \multirow{5}{*}{ CC } & al & $.86^{* * *}$ & .74 & \multirow{5}{*}{.60} & \multirow{5}{*}{.88} \\
\hline & $\mathrm{a} 2$ & $.83^{* * *}$ & .70 & & \\
\hline & a3 & $.86^{* * *}$ & .74 & & \\
\hline & $\mathrm{a} 4$ & $.72^{* * *}$ & .51 & & \\
\hline & a5 & $.57^{* * *}$ & .33 & & \\
\hline \multirow{6}{*}{ CT } & $\mathrm{cl}$ & $.78^{* * *}$ & .60 & \multirow{6}{*}{.50} & \multirow{6}{*}{.86} \\
\hline & $c 2$ & $.74^{* * *}$ & .55 & & \\
\hline & c3 & $.65^{* * *}$ & .43 & & \\
\hline & $c 4$ & $.76^{* * *}$ & .58 & & \\
\hline & $c 5$ & $.68^{* * *}$ & .46 & & \\
\hline & c6 & $.63^{* * *}$ & .39 & & \\
\hline \multirow{6}{*}{ IP } & $\mathrm{rl}$ & $.74^{* * *}$ & .54 & \multirow{6}{*}{.64} & \multirow{6}{*}{.91} \\
\hline & r2 & $.86^{* * *}$ & .73 & & \\
\hline & r3 & $.89^{* * *}$ & .78 & & \\
\hline & $\mathrm{r} 4$ & $.87^{* * *}$ & .75 & & \\
\hline & r5 & $.82^{* * *}$ & .67 & & \\
\hline & r6 & $.59^{* * *}$ & .34 & & \\
\hline \multirow{6}{*}{ EP } & $\mathrm{d} 1$ & $.77^{* * *}$ & .59 & \multirow{6}{*}{.58} & \multirow{6}{*}{.89} \\
\hline & $\mathrm{d} 2$ & $.80^{* * *}$ & .65 & & \\
\hline & $\mathrm{d} 3$ & $.79^{* * *}$ & .63 & & \\
\hline & $\mathrm{d} 4$ & $.73^{* * *}$ & .54 & & \\
\hline & $\mathrm{d} 5$ & $.75^{* * *}$ & .56 & & \\
\hline & d6 & $.71^{* * *}$ & .51 & & \\
\hline \multirow{5}{*}{ LE } & 11 & $.78^{* * *}$ & .61 & \multirow{5}{*}{.63} & \multirow{5}{*}{.89} \\
\hline & 12 & $.83^{* * *}$ & .69 & & \\
\hline & 13 & $.86^{* * *}$ & .73 & & \\
\hline & 14 & $.72^{* * *}$ & .52 & & \\
\hline & 15 & $.76^{* * *}$ & .58 & & \\
\hline \multirow{6}{*}{ CME } & s1 & $.83^{* * *}$ & .68 & \multirow{6}{*}{.73} & \multirow{6}{*}{.94} \\
\hline & s2 & $.85^{* * *}$ & .72 & & \\
\hline & s3 & $.85^{* * *}$ & .72 & & \\
\hline & s4 & $.87^{* * *}$ & .75 & & \\
\hline & s5 & $.86^{* * *}$ & .73 & & \\
\hline & s6 & $.86^{* * *}$ & .74 & & \\
\hline
\end{tabular}

Note. L.V.: latent variable; O.V.: observed variable; SFL: standardized factor loading. SMC $\left(R^{2}\right)$ : square multiple correlation.

AVE: average variance extracted; C.R.: composite reliability; ${ }^{* * *} P<.001$.

As shown in Table 5, al and a3 are the max $\left(R^{2}=.74\right)$ among 10 observed variables' $R^{2}$ of CRC, and they means that CR can inspire human nature and has far-reaching implication for people. Perennialism education also emphasized those [55]. Thus, those results are similar to the view on Perennialism education. $\mathrm{r} 3$ is the $\max \left(R^{2}=.78\right)$ among 12 observed variables' $R^{2}$ of CRP, and it means that CR achievement exhibitions are usually held for the purposes of offering community residents to know CR. Bagin and Gallagher [56] claim that there is a school public relation between the school and community. Thus, the school wants to establish relationships with the community through CR achievement exhibitions. $\mathrm{s} 4$ is the $\max \left(R^{2}=.75\right)$ among 12 observed variables' $R^{2}$ of CRE, and it means that CR contributes to 
practice life education. Bandura [57] shows that individual behaviors change through observational learning or modeling. The students always regard sages as models in CR teaching and then their behaviors change in a positive direction gradually through observational learning or modeling.

\section{Conclusion}

The fit of the external and internal structure of model 1 is good. It indicates that CRC and CRP positively influence CRE from Figure 3. In other words, the Operation factor influences the Service factor for CR education's CORPS model. The results of the SEM construction and verification of this study are consistent with the CR literature and CORPS framework. The results of this study can not only conducive to facilitating CRC, CRP, and CRE but also provide the management policy for the CR education in ESs. This study also shows that both CORPS framework can apply to CR education management and the overall CR plans play an important role for CR education in ESs. Especially, the findings of this study contribute to achieving the sustainable management for the CR education in ESs.

Furthermore, this study suggests that the educational institutions or ESs should always hold the CR education workshops for school faculties and CR volunteers to enhance their CR philosophy and CR teaching; ESs should plan more CR activities inside/outside schools to promote CR education; ESs should increase manpower and resources about CR education. Finally, the further research is to investigate the influences of manpower and resources on CRE.

\section{Conflict of Interests}

The authors declare that there is no conflict of interests regarding the publication of this paper.

\section{Acknowledgments}

The authors are grateful to Global Classics-Reading Education Foundation, Professor Tsai-Kui Wang, Miss Shu-Kui Tsai, and numerous principals, directors, teachers, and classics-reading volunteers for their kind assistance.

\section{References}

[1] T. K. Wang, The Handbook of Classics for Children Education, Language Teaching \& Research Center, National Taichung University of Education, Taichung, Taiwan, 1995, (Chinese).

[2] International Cultural Institute, A Guide for Children's ClassicsReading: Global Promotion of Classics-Reading Education for Children by Mr. Nan Huai-Chin, Laoku, Taipei, Taiwan, 2007, (Chinese).

[3] H. Zhou, "The first lesson of the new century: character decided win and lose-fture talented person's secret," CommonWealth Magazine, vol. 14, 2004 (Chinese).

[4] Character Counts, “The six pillars of character," 2008, http:// charactercounts.org/sixpillars.html.

[5] R. B. Cooter Jr., "Teacher "capacity-building” helps urban children succeed in reading," Reading Teacher, vol. 57, no. 2, pp. 198205, 2003.
[6] X. D. Liu, Blind and Save: Evaluation of Children's Classics-Reading, Education, Jiangsu, China, 2009, (Chinese).

[7] T. T. Pan, "Analysis of Tsai-Kuei Wang's theory of childhood education centered on the recitation of Chinese ancient classics," Studies in the Humanities and Social Science, vol. 9, pp. 5596, 2008 (Chinese).

[8] J. Q. Guo, "The requirement for children to read classics is abreast of the times," Journal of Educational Studies, vol. 3, no. 2, pp. 29-34, 2007 (Chinese).

[9] Department of Education and Hualien County Government, "2012 Workshop of promotion of classics-reading education for teachers" (Chinese), 2011, http://www.yam.ks.edu.tw/

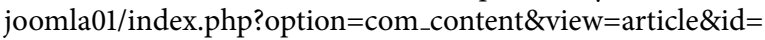
627\&Itemid $=544$.

[10] Department of Education, Hualien County Government, "2012 workshop of promotion of classics-reading education for teachers," 2011, (Chinese), http://teacher.hlc.edu.tw/imain9.asp?id= 365\&sid $=448$.

[11] Ministry of Education, "The 2009 implementation plan for the teacher training seminars in 7 counties/cities in Southern Taiwan during the summer vacation," 2009, (Chinese), http://163 .32.48.5/data/pub/200906031026070.doc.

[12] Department of Education, Hualien County Government, "The implementation plan for promoting classics-reading for children in Hualien County," 2010, (Chinese), http://teacher.hlc.edu .tw/imain9. asp?id=365\&sid=448.

[13] Epoch Times, "Founding of the classics-reading foundation, propagating classics-reading to the world: classics-reading can help students learn more about the Chinese culture, increase their concentration, improve their behaviors, and treat their learning disabilities," 2007, (Chinese), http://hk.epochtimes .com/7/1/8/37905.htm.

[14] Fu Chih Cultural and Educational Foundation, Explanation of Classics-Reading, Fu Chih, Taipei, Taiwan, 1999, (Chinese).

[15] C. J. Yang, A Case Study of the Application of Reading Chinese Classics Approach in Elementary School, Graduate Institute of Education, National Taitung University, Taitung, Taiwan, 2005, (Chinese).

[16] T. K. Wang, "The basic principles of classics-reading education," 2012, (Chinese), http://bbs.gsr.org.tw/cgi-bin/topic.cgi?forum= $14 \&$ topic $=476 \&$ show $=0$.

[17] Y. H. Weng, The Research of Teacher's Teaching Beliefs in the Children's Classics-Memorizing Programs, Graduate Institute of Educational Entrepreneurship and Management, National University of Tainan, Tainan, Taiwan, 2008, (Chinese).

[18] H. R. Chang, The Learning Process of Classics Education [M.S. thesis], Graduate Institute of Curriculum and Instruction, Mingdao University, Taichung, Taiwan, 2012, (Chinese).

[19] Y. F. Wang, Research on the Attitude, Teaching Process and Effect of the Children Poem Study Class-the Example of Three Primary Schools in Taichung County, Institute of National Education, National Hualian Teachers College, Hualian, Taiwan, 1999, (Chinese).

[20] Shihchuan Elementary School, "Shihchuan classics-reading website," 2009, (Chinese), http://classweb.scps.kh.edu.tw/Homepage.php?teacher_id=123.

[21] Ruimei Elementary School, "The implementation plan for characteristic development of new ways to read classics," 2010, (Chinese), http://host.rmes.tyc.edu.tw/ cer2/01/02.doc.

[22] Y. H. Chen, The Study of Applying Classics-Reciting Education Programs in Elementary Schools, Department of Language and 
Literacy Education, National Taichung University of Education, Taichung, Taiwan, 2009, (Chinese).

[23] C. Y. Chen, L. F. Cheng, and C. J. Jiang, The Business Trip Report to Mainland China (Type of Trip: Visiting), Suzhou-Taipei Chinese Classic Poems and Prose Exchange Activity Series, Dalong Elementary School, Taipei, Taiwan, 2011, (Chinese).

[24] D. S. Lin, "Study on classics-reading education in curriculum of the elementary school," in Proceedings of the 2nd Taiwan International Symposium of Confucianism, 1999, (Chinese).

[25] S. C. Chang, A Study on the Effect of Chinese Classics Reading Teaching for the Elementary Students, Graduate School of Curriculum and Instruction, National Taipei University of Education, Taipei, Taiwan, 2001, (Chinese).

[26] C. Y. Yen, A Case Study of Child Classics-Reciting Education Implemented in Zheng Dian Elementary School in Taichung, Department of Education, National Taichung University of Education, Taichung, Taiwan, 2012, (Chinese).

[27] T. P. Huang, A Study of Children's School Achievements in Classics-Reading [M.S. thesis], Department of Education, National Taichung University of Education, Taichung, Taiwan, 2012, (Chinese).

[28] D. L. Tsui, Effects of Children's Classical Reading Classes on the Character Development of Elementary School Students, Department of Adult \& Continuing Education, National Taiwan Normal University, Taipei, Taiwan, 2011, (Chinese).

[29] C. H. Chen, A Case Study: The Effects on Reading Motivation of Children's Reading-Classics at Home Schooling, Graduate Institute of Education, National Sun Yat-Sen University, Kaohsiung, Taiwan, 2006, (Chinese).

[30] H. W. Tsai, Social Observation on Child Classics-Reciting-Three Examples in Chiayi Classics-Reciting Classes, Department of Applied Sociology and Institute of Sociology, Chiayi, Taiwan, 2011, (Chinese).

[31] A. B. Chu, "Report of the achievements of implementing classics-reading education," Classics-Reading Magazine, vol. 12, 1998 (Chinese).

[32] B. R. Yao, "The educational reflexive meaning on the movement of memorization of traditional classics in childhood (I)," in Education and Society: Introspection of Sociology of Education in the Coming Age of Information, pp. 51-81, Yang-Chih Book, Taipei, Taiwan, 2000, (Chinese).

[33] B. J. Bitter and K. R. George, "The exemption of nonprofit organizations from federal income taxation," Yale Law Journal, vol. 85, pp. 229-358, 1976.

[34] B. A. Weisbrod, To Profit or Not to Profit: The Commercial Transformation of the Nonprofit Sector, Cambridge University Press, Cambridge, UK, 2003.

[35] D. H. Seetoo, The Nongovernmental Organization's Management, Commonwealth Publishing, Taipei, Taiwan, 1999, (Chinese).

[36] M. H. Chen, Study on Current Situation Obstacles and Solutions of Reading Classics in Childhood in Primary Schools in Penghu County [M.S. thesis], Master's Program of Curriculum and Instruction, Department of Education, National University of Tainan, Tainan, Taiwan, 2008, (Chinese).

[37] H. W. Xie, The Study of Classics-Reading Education for Shitan Junior High School in Miaoli Country, Department of Chinese Literature, National Taiwan University, Taipei, Taiwan, 2009, (Chinese).

[38] M. F. Yang, The Teaching Beliefs of Five Teachers in the Classics-Memorizing Programs, Graduate Institute of Education,
National Chung Cheng University, Chiayi, Taiwan, 2001, (Chinese).

[39] R. S. Chuang, An Observational Study of a Children's Class with Classics-Reading Implemented, Graduate Institute of Compulsory Education, National Chiayi University, Chiayi, Taiwan, 2002, (Chinese).

[40] H. E. Tinsley and D. J. Tinsley, "Uses of factor analysis in counseling psychology research," Journal of Counseling Psychology, vol. 34, no. 4, pp. 414-424, 1987.

[41] J. Hair, R. Anderson, R. Tatham, and W. Black, Multivariate Data Analysis with Readings, Prentice-Hall International, Englewood Chiffs, NJ, USA, 4th edition, 1995.

[42] Y. Reisinger and L. Turner, "Structural equation modeling with Lisrel: application in tourism," Tourism Management, vol. 20, no. 1, pp. 71-88, 1999.

[43] Department of Statistics and Ministry of Education, "Important educational statistics information" (Chinese), 2011, https://stats .moe.gov.tw/files/gender/302-2.xls.

[44] Ministry of the Interior, "Monthly bulletin of interior statistics," 2012, (Chinese), http://sowf.moi.gov.tw/stat/month/list.htm.

[45] C. A. Tang, "A study of the current situation of classics-reading education in Taiwan and China," Journal of Cultural and Creative Industries Research, vol. 2, no. 3, pp. 243-254, 2012 (Chinese).

[46] L. J. Cronbach, "Coefficient alpha and the internal structure of tests," Psychometrika, vol. 16, no. 3, pp. 297-334, 1951.

[47] K. A. Bollen, Structural Equations with Latent Variables, John Wiley \& Sons Inc., New York, NY, USA, 1989.

[48] L. T. Hu and P. Bentler, "Evaluating model fit," in Structural Equation Modeling: Concepts, Issues, and Applications, R. H. Hoyle, Ed., pp. 76-99, Sage, London, UK, 1995.

[49] M. W. Browne and R. Cudeck, "Alternative ways of assessing model fit," in Testing Structural Equation Models, K. A. Bollenand and J. S. Long, Eds., pp. 136-162, Sage, Kern County, Calif, USA, 1993.

[50] C. R. Fornell and F. F. Larcker, "Structural equation models with unobservable variables and measurement error," Journal of Marketing Research, vol. 18, pp. 39-51, 1981.

[51] R. B. Kline, Principles and Practice of Structural Equation Modeling, Guilford Press, New York, NY, USA, 2005.

[52] R. P. Bagozzi and Y. Yi, "On the evaluation of structural equation models," Journal of the Academy of Marketing Science, vol. 16, no. 1, pp. 74-94, 1988.

[53] C. M. Liao, A Study of the Influences of Implementing ClassicsReading Education in Elementary Schools on Improving Children's Self-Concept, Department of Language and Literacy Education, National Taichung University of Education, Taichung, Taiwan, 2003, (Chinese).

[54] Y. P. Song, The Action Research of the Effects of Classics-reading Lessons on the Learning Methods, Learning Attitudes, and Scholastic Achievements in Mandarin Chinese for the Pupils in a Rural Elementary School, Department of Education, National Kaohsiung Normal University, Kaohsiung, Taiwan, 2008, (Chinese).

[55] A. Ornstein and F. Hunkins, Curriculum: Foundation, Principles, and Issues, Pearson, Boston, Mass, USA, 2004.

[56] D. Bagin and D. R. Gallagher, The School and Community Relations, Allyn and Bacon, Needham Heights, Mass, USA, 7th edition, 2001.

[57] A. Bandura, Social Learning Theory, Prentice Hall, Englewood Cliffs, NJ, USA, 1985. 


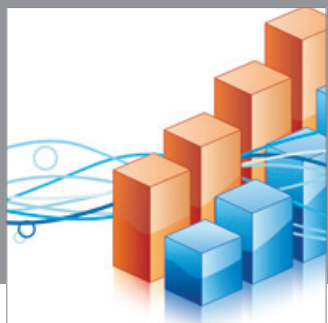

Advances in

Operations Research

mansans

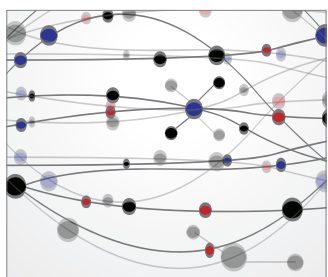

The Scientific World Journal
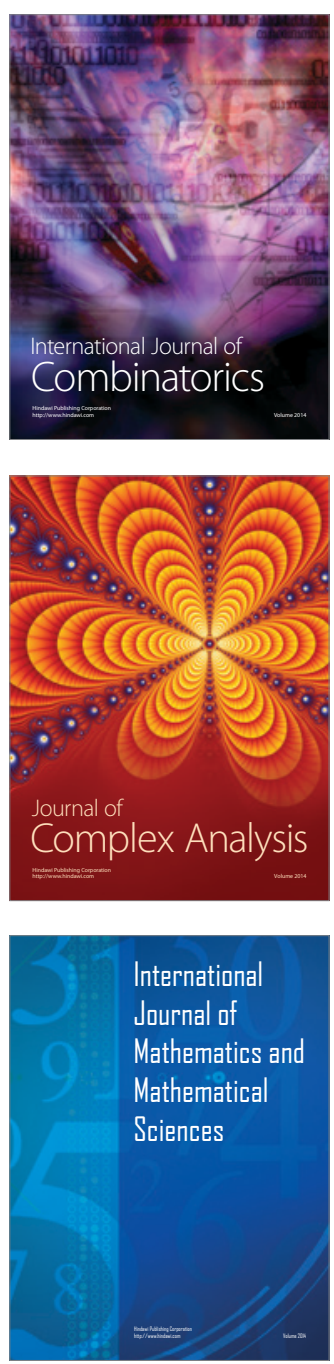
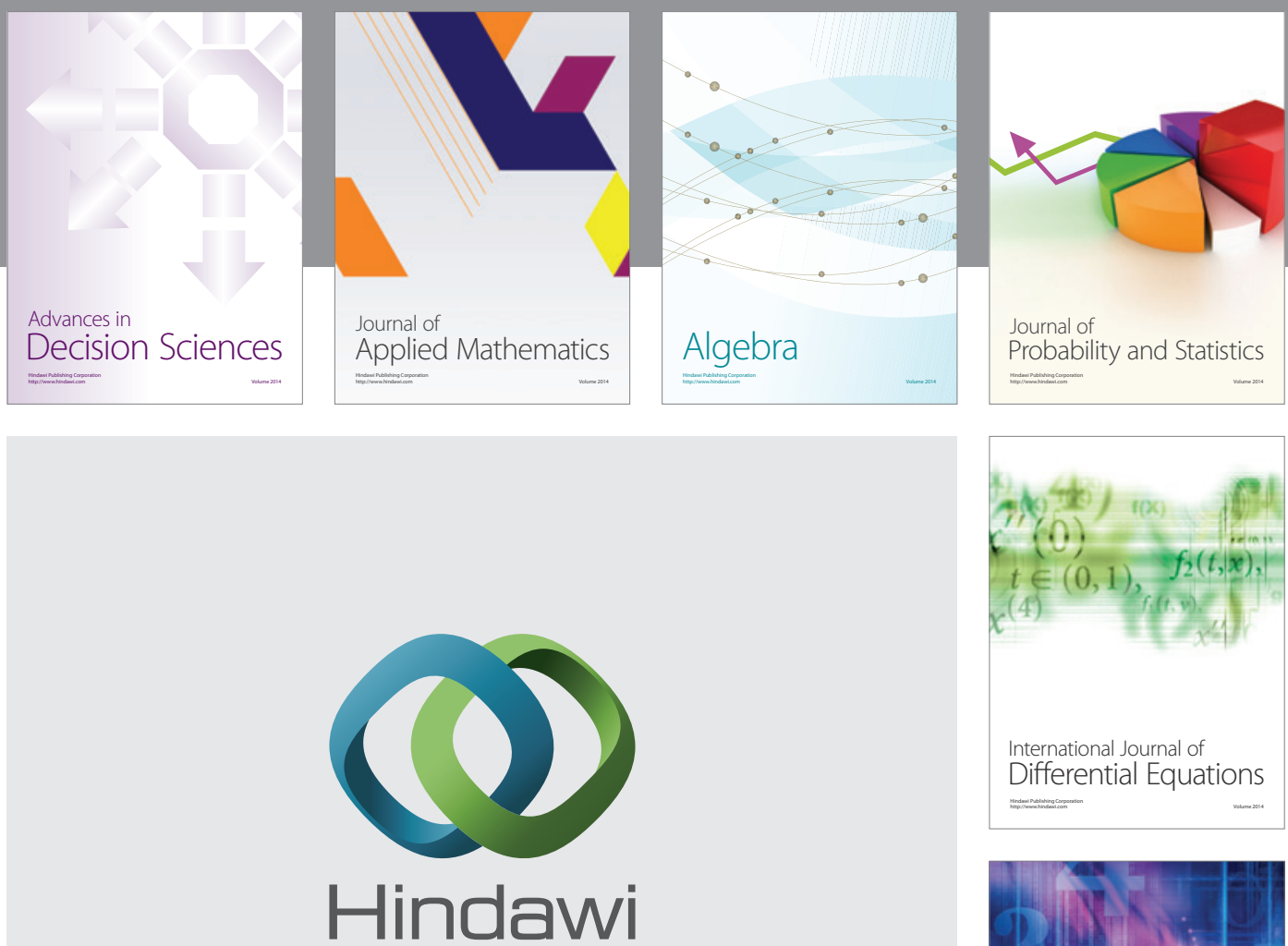

Submit your manuscripts at http://www.hindawi.com
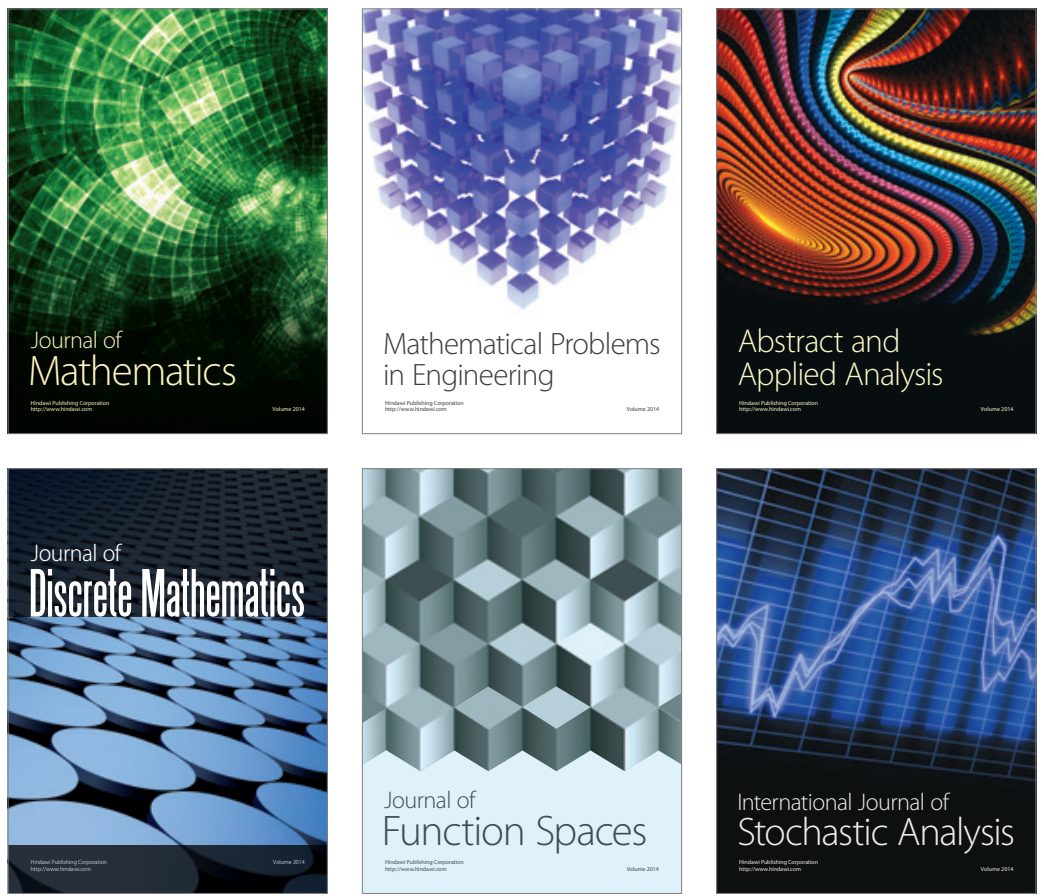

Journal of

Function Spaces

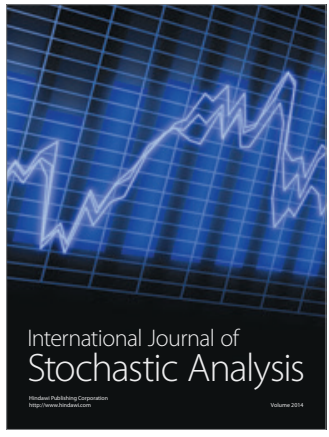

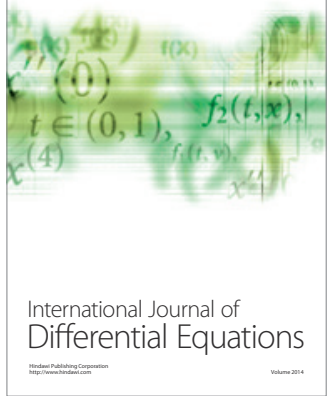
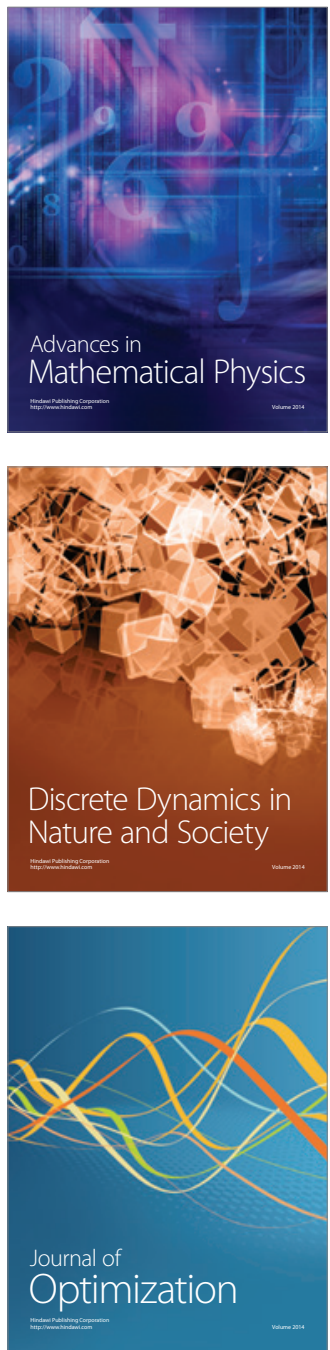